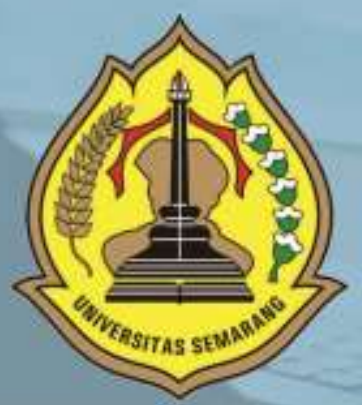

P-ISSN: 1412-5331, E-ISSN: 2716-2532 MAJALAH ILMIAH FAKULTAS EKONOMI UNIVERSITAS SEMARANG

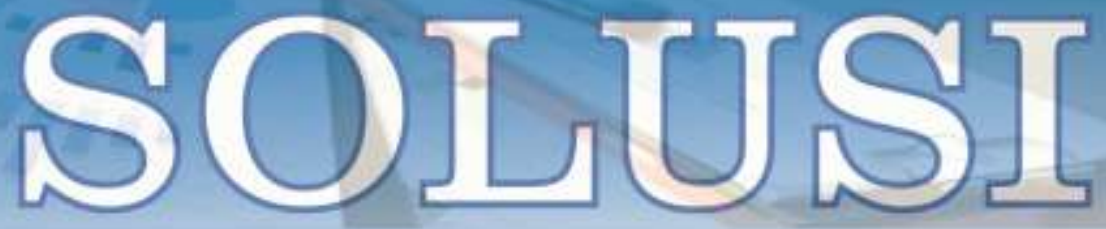

PENGARUH TINGKAT LITERASI KEUANGAN, SIKAP INDIVIDU TERHADAP MINAT INVESTASI SAHAM DI KALANGAN MAHASISWA S2 MAGISTER MANAJEMEN UNIVERSITAS SEMARANG (Asah Wiari Sidiq: Asih Niati - Universitas Semarang)

PENINGKATAN KINERJA PENGAJARAN DOSEN MELALUI KEPEMIMPINAN TRANSFORMASIONAL DAN PEMENUHAN KEBUTUHAN PSIKOLOGIS DASAR DENGAN PEMEDIASI MOTIVASI KER.JA (Anik Herminingsih - Universitas Mercu Buana)

PENGARUH PAJAK, TUNNELING INCENTIVE DAN GOOD CORPORATE GOVERNANCE (GCG) DAN MEKANISME BONUS TERHADAP INDIKASI TRANSFER PRICING PADA PERUSAHAAN MANUFAKTUR (Arum Sasi Andayani; Andiani Ika Sulistyanuati - Liniversitas Semarang)

PENGELOLAAN ALOKASI DANA DESA: AKUNTABILITAS DAN TRANSPARANSI (STUDI KASUS PADA DESA GINGGANGTANI, KECAMATAN GUBUG, KABUPATEN GROBOGAN) (Ana Rokhatt: Saifidin: Dian Trivani - Universitas Semarang)

PENERAPAN STRATEGI BAURAN PEMASARAN PADA USAHA KECIL TELUR ASIN DI KELURAHAN TEGAL SARI, KECAMATAN CANDI SARI, SEMARANG (Nisa Novia Avien Christy; Dwi Widi Pratito - Universitas Semarang)

FAKTOR-FAKTOR YANG MEMPENGARUHI PROFITABILITAS LEMBAGA PERKREDITAN DESA (LPD) DI KABUPATEN BADUNG (Ida Ayu Nyoman Yuliastuti, Putu Kepramareni, I Gusti Ayu Asta Yunisari - Universitas Mahasaraswati Denpasar)

KEBERHASILAN MEMPERTAHANKAN WARUNG MAKAN PRASMANAN MBAH SAN (Sri Wulandari: Susanto - Universitas Semarang)

BRAND PERSONALITY DAN GENDER BRAND PERSONALITY STRATEGI MEMBANGUN MEREK (Haris Murwanto - Universitas Semarang)

POLA PERMINTAN DAN PENAWARAN KETERSEDIAAN DAGING SAPI NASIONAL TAHUN 2030 DENGAN PENDEKATAN FORECASTING (Moeljono - Universitas Semarang)

PENGARUH BRAND IMAGE, KUALITAS PRODUK, PERSEPSI HARGA TERHADAP KEPUTUSAN PEMBELIAN (STUDI KASUS PADA PRODUK SUSU NATURSOYA CV. GLOBAL MANDIRI SEJAHTERA KANCA PURWODADI)

(Ajeng Ayr Fatimah P: Soedarmadi - Untversitas Semarang) 


\section{DESKRIPSI}

Majalah IImiah Solusi Mengkaji

Masalah-Masalah Sosial,

Ekonomi dan Bisnis

\section{KETERANGAN TERBIT}

Terbit Pertama Kali Juli 2002

dan SelanjutnyaTerbit Tiga Bulan

Sekali (Januari, April, Juli dan

Oktober)

\section{PENERBIT}

Fakultas Ekonomi USM

\section{ALAMAT PENERBIT}

JL. Soekarno Hatta Semarang

Telp. 024-6702757 Fax. 024-6702272

\section{PENGELOLA}

Editor in Chief : Yohanes Suhardjo, SE, M.Si., Ak, CA Vice Editor Chief : Sugeng Rianto, SE, MM

Managing Editor: Edy Suryawardana, SE, MM

Secretary of Managing Editor : Asih Niati, SE, MM

Administration \& Circulation :

Citra Rizkiana, SE, MM

Layout \& Typesetting : M Burhan Hanif S.Kom, M.Kom

Board of Editors:

1. Prof. Dr. Ir. Kesi Widjajanti, SE, MM (USM)

2. Prof. Drs. Mohammad Nasir, Msi, Ph.D, AK. (USM)

3. Prof. Supramono SE, MBA, DBA (UKSW)

4. Prof. Drs. H. Imam Ghozali, M.Com, Akt, PhD (UNDIP)

5. Prof. Dr. Agus Suroso, MS (UNSOED)

6. Prof. Dr. Widodo, SE, M.Si (UNISSULA)

7. Prof. Dr. Dra. Sulastri, ME, M.Kom (UNSRI)

8. Dr. Ardiani Ika S, SE, MM, Ak, CA, CPA (USM)

\section{KATA PENGANTAR}

Sungguh merupakan kebahagiaan tersendiri bagi kami, takala kami dapat hadir rutin setiap tiga bulan sekali untuk saling bertukar pikiran mengenai hal-hal baru dibidang sosial, ekonomi dan bisnis.

Pada kesempatan ini penerbit menyampaikan terima kasih kepada semua pihak yang telah mengirimkan artikel-artikelnya. Penerbit akan membuka kesempatan seluas-luasnya bagi seluruh kalangan akademisi maupun praktisi baik dari dalam maupun luar Universitas Semarang untuk mempublikasikan karya ilmiahnya.

Penerbitan majalah ilmiah "SOLUSI" kali ini menghadirkan 10 (Sepuluh) artikel yang kami anggap layak untuk diterbitkan, dengan harapan dapat menjadi tambahan referensi bagi para pembaca dan menjadi sumbangan pengembangan persemaian khasanah pengetahuan dibidang sosial, ekonomi dan bisnis.

Akhir kata semoga majalah ilmiah "SOLUSI" dapat memberi manfaat yang sebesar-besarnya.

Hormat Kami 


\section{DAFTAR ISI}

PENGARUH TINGKAT LITERASI KEUANGAN, SIKAP INDIVIDU

TERHADAP MINAT INVESTASI SAHAM DI KALANGAN MAHASISWA S2 MAGISTER MANAJEMEN UNIVERSITAS SEMARANG

(Asah Wiari Sidiq; Asih Niati - Universitas Semarang).......

PENINGKATAN KINERJA PENGAJARAN DOSEN MELALUI

KEPEMIMPINAN TRANSFORMASIONAL DAN PEMENUHAN KEBUTUHAN PSIKOLOGIS DASAR DENGAN PEMEDIASI MOTIVASI KERJA

(Anik Herminingsih - Universitas Mercu Buana)

PENGARUH PAJAK, TUNNELING INCENTIVE DAN GOOD CORPORATE GOVERNANCE (GCG) DAN MEKANISME BONUS TERHADAP INDIKASI TRANSFER PRICING PADA PERUSAHAAN MANUFAKTUR

(Arum Sasi Andayani; Ardiani Ika Sulistyawati - Universitas Semarang)

PENGELOLAAN ALOKASI DANA DESA: AKUNTABILITAS DAN TRANSPARANSI

(STUDI KASUS PADA DESA GINGGANGTANI, KECAMATAN GUBUG, KABUPATEN GROBOGAN)

(Ana Rokhati; Saifudin; Dian Triyani - Universitas Semarang).

PENERAPAN STRATEGI BAURAN PEMASARAN PADA USAHA KECIL TELUR ASIN DI KELURAHAN TEGAL SARI, KECAMATAN CANDI SARI, SEMARANG

(Nisa Novia Avien Christy; Dwi Widi Pratito - Universitas Semarang)

FAKTOR-FAKTOR YANG MEMPENGARUHI PROFITABILITAS LEMBAGA PERKREDITAN DESA (LPD) DI KABUPATEN BADUNG

(Ida Ayu Nyoman Yuliastuti; Putu Kepramareni; I Gusti Ayu Asta Yunisari - Universitas Mahasaraswati Denpasar)..... .75

KEBERHASILAN MEMPERTAHANKAN WARUNG MAKAN PRASMANAN MBAH SAN

(Sri Wulandari; Susanto - Universitas Semarang).....

BRAND PERSONALITY DAN GENDER BRAND PERSONALITY STRATEGI MEMBANGUN MEREK

(Haris Murwanto - Universitas Semarang).

POLA PERMINTAN DAN PENAWARAN KETERSEDIAAN DAGING SAPI NASIONAL TAHUN 2030 DENGAN PENDEKATAN FORECASTING

(Moeljono - Universitas Semarang)......

PENGARUH BRAND IMAGE, KUALITAS PRODUK, PERSEPSI HARGA TERHADAP KEPUTUSAN PEMBELIAN (STUDI KASUS PADA PRODUK SUSU NATURSOYA CV. GLOBAL MANDIRI SEJAHTERA KANCA PURWODADI)

(Ajeng Ayu Fatimah P; Soedarmadi - Universitas Semarang) 


\title{
BRAND PERSONALITY DAN GENDER BRAND PERSONALITY STRATEGI MEMBANGUN MEREK
}

\author{
Haris Murwanto
}

\author{
haris.murwanto@usm.ac.id
}

\author{
Fakultas Ekonomi Universitas Semarng
}

Diterima: November 2019, Disetujui:Desember 2019,Dipublikasikan: Januari 2020

\begin{abstract}
Brand is a thing that must be owned and attached to the product if you want the product to be accepted by consumers. In making a brand, a brand must have tangible and intangible aspects. Tangible aspects consisting of name, logo, slogan and packaging, this is related to the perception that the brand wants to build. Visually, the logo is well made, including the color that is easy to remember, easily represents a product in terms of benefits and usability and reflects the quality of the product. Intangible aspects consisting of brand values and image will be obtained from the brand's reputation.

In creating, defining and building a brand, it should be considered carefully what brand personality will be owned by the brand, if it is already known that the target market to be entered will be easier to form brand personality on the brand. If the target market of the product is simple and cheerful people, then the brand personality is focused on the dimension of sincerity, if the target market is dynamic personality people who focus on the excitement dimension, if you want the target market of people who are confident then focus on the competence dimension (competence), if the target market is people who like glamor and look charming can focus on the dimension of sophistication (sophistication) and if you want to target the market of people who are adventurous, good looking then focus on the dimension ruggedness. Another alternative is a combination of several existing brand personality dimensions.
\end{abstract}

Keywords: Brand Personality, Gender, Strategy

\begin{abstract}
ABSTRAK
Merek adalah hal yang harus dimiliki dan melekat pada produk apabila menginginkan produk dapat diterima oleh konsumen. Dalam membuat merek, sebuah merek harus memiliki aspek tangible dan intangible. Aspek tangible yang terdiri dari nama, logo, slogan dan kemasan, hal ini berkaitan dengan persepsi yang ingin dibangun dari merek tersebut. Secara visual, logo dibuat dengan baik termasuk pemberian warna agar mudah diingat, mudah merepresentasikan sebuah produk dalam hal manfaat dan kegunaan serta mencerminkan kualitas produk. Aspek intangible yang terdiri dari nilai dan citra merek akan didapat dari reputasi merek tersebut.

Dalam membuat, menetapkan dan membangun merek, hendaknya diperhatikan dengan seksama brand personality seperti apa yang akan dimiliki oleh merek tersebut, jika sudah diketahui target pasar yang akan dimasuki akan lebih mudah membentuk brand personality pada merek tersebut. Jika target pasar produk tersebut adalah orang-orang yang bersifat sederhana dan ceria maka brand personality difokuskan kepada dimensi sincerity (ketulusan), jika target pasarnya adalah orang-orang yang berkepribadian dinamis fokus pada dimensi excitement (kegembiraan), jika ingin target pasarnya orangorang yang percaya diri maka fokus pada dimensi competence (kompetensi), jika target pasarnya orangorang yang senang glamor dan tampil mempesona dapat fokus pada dimensi sophistication (kecanggihan) dan jika ingin target pasar orang-orang yang senang bertualang, berpenampilan gagah maka fokus pada dimensi ruggedness (ketangguhan). Alternatif lain adalah gabungan dari beberapa dimensi brand personality yang ada.
\end{abstract}

Kata Kunci : Brand Personality, Gender, Strategi 


\section{PENDAHULUAN}

Bagi seorang pengusaha atau perusahaan, merek merupakan ujung tombak dari rangkaian kegiatan bisnis yang dilakukankarena dari merk itu konsumen akan mendapatkan gambaran mengenai sebuah produk baik itu jaminan kualitas, kemasan, warna, rasa dan segala atribut yang melekat pada produk tersebut, merek juga sebagai pembeda antara satu produk dengan produk lain. Menurut Undang-Undang Merek (Undang-Undang Republik Indonesia Nomor 15 Tahun 2001 Tentang Merek, 2001), merek adalah tanda yang berupa gambar, nama, kata, huruf-huruf, angka-angka, susunan warna, atau kombinasi dari unsur-unsur tersebut yang memiliki daya pembeda dan digunakan dalam kegiatan perdagangan barang atau jasa.

Merek juga dapat memberikan persepsi kepada konsumen tentang sebuah produk, konsumen akan menganggap sebuah produk itu baik atau berkualitas hanya dengan membaca mereknya saja tanpa harus melihat dan meneliti langsung produk tersebut. Menurut Kotler dan Lane (2012) dalam (Rizan, Handayani, \& Kresnamurti, 2015) citra merek adalah penglihatan dan kepercayaan yang terpendam konsumen, sebagai cerminan asosiasi yang tertahan diingatan konsumen. David A. Aaker (1996) dalam Murwanto dan Indriana mengatakan asosiasi/citra merek membantu konsumen untuk mengingat kembali informasi yang diperlukan dalam proses pengambilan keputusan dan menciptakan kesan positif pada konsumen itu sendiri, selain itu citra merek yang tinggi umumnya dimiliki oleh merek tersebut yaitu diposisikan dengan baik di benak konsumen (Murwanto \& Indriana, 2016).

Kita ketahui beberapa produk sebelumnya tidak diberi merek seperti gula dan garam, saat ini produk-produk tersebut sudah diberi merek dan terdapat berbagai variasi produk, para produsen atau penjual makin sadar pentingnya merek karena merek tidak saja bermanfaat bagi penjual tetapi juga bermanfaat bagi pembeli. Menurut Kottler (1998) dalam (Rahab, 2009) manfaat merek bagi pembeli adalah :

1. Merek dapat menceritakan sesuatu kepada pembeli tentang mutu produk

2. Merek dapat membantu menarik perhatian konsumen terhadap produk-produk baru yang mungkin bermanfaat bagi konsumen.

Sedangkan manfaat merek bagi penjual adalah :

1. Memudahkan penjual mengolah pesanan dan memnelusuri masalah-masalah yang muncul 
2. Memberikan perlindungan hukum atas keistimewaan produk yang unik agar tidak mudah ditiru oleh pesaing.

3. Memungkinkan menarik sekelompok pelanggan yang setia dan menguntungkan

4. Membantu penjual melakukan segmentasi pasar

Begitu strategisnya peran merek saat ini hingga perlu dikelola secara khusus, manajemen merek adalah proses pengelolaan merek sebuah organisasi/perusahaan yang bertujuan untuk meningkatkan ekuitas merek dalam jangka panjang, sehingga beberapa perusahaan menempatkan personalia khusus untuk mengelola merek. Manajer merek (Brand Manager) bertugas merancang dan mengelola agar merek terjaga identitasnya dan dapat beresonansi dengan para pelanggan dan konsumen potensial. Beberapa perusahaan yang memiliki manajer khusus di bidang merek atau brand manager antara lain PT. Indofood Sukses Makmur dan PT. Unilever Indonesia. Perusahaan-perusahaan tersebut termasuk perusahaan yang memiliki multi produk yang tentunya memiliki banyak merek untuk masing-masing produk. Mereka sadar dan menganggap peran merek bagi produk-produk mereka sangat strategis dan menjadi faktor penting memunculkan minat beli dan keputusan pembelian produk bahkan merek dapat memiliki nilai (value) yang luar biasa apabila dikelola dengan baik, seperti terlihat pada tabel berikut ini :

Tabel 1.

Merek Dengan Nilai Termahal di Indonesia Tahun 2018 Versi Brandz Top

\begin{tabular}{|r|l|l|l|l|}
\hline No & \multicolumn{1}{|c|}{ Merek } & \multicolumn{1}{|c|}{ Perusahaan } & \multicolumn{1}{c|}{ Bisnis Utama } & Nilai (USD) \\
\hline \hline 1 & BCA & PT. Bank Central Asia & Perbankan & 12,67 Milyar \\
\hline 2 & BRI & PT. Bank Rakyat Indonesia & Perbankan & 9, 39 Milyar \\
\hline 3 & Telkomsel & PT. Telekomunikasi Seluler & Telekomunikasi & 8,86 Milyar \\
\hline 4 & A Mild & PT. HM Sampurna & Rokok & 8,28 Milyar \\
\hline 5 & Mandiri & Bank Mandiri & Perbankan & 6,43 Milyar \\
\hline 6 & Dji Sam Soe & PT. HM Sampurna & Rokok & 2,65 Milyar \\
\hline 7 & Gojek & PT. Gojek Indonesia & Transportasi Online & 2,39 Milyar \\
\hline 8 & Surya & PT. Gudang Garam & Rokok & 2,37 Milyar \\
\hline 9 & Gudang Garam & PT. Gudang Garam & Rokok & 2,31 Milyar \\
\hline 10 & BNI & PT. Bank Negara Indonesia & Perbankan & 2,23 Milyar \\
\hline
\end{tabular}

Sumber : ("Merek Termahal di Indonesia 2018," n.d.) Diolah untuk penelitian ini (Akses 22-11-2019 21:50) 
Untuk nama merek BCA, yang bergerak dalam bidang perbankan, nilai mereknya jika akan dijual maka setara dengan Rp. 177,38 Trilyun (kurs Rp. 14.000/USD) belum termasuk aset. Nilai merek yang sangat fantastis tersebut tidak dicapai dengan mudah, perlu komitmen yang tinggi dan waktu yang panjang.

Brand personality menjadi faktor penting dewasa ini karena konsumen tidak hanya membeli produk untuk memenuhi kebutuhan konsumtif saja tetapi juga untuk mengekspresikan diri sehingga dengan brand personality yang tepat maka dapat lebih mudah untuk menentukan segmen pasar yang dituju. Selain itu, gender brand personality atau pemisahan brand personality berdasarkan gender (pria dan wanita), juga dapat digunakan untuk mempermudah penentuan segmen pasar suatu produk ( $\mathrm{Wu}$, Klink, \& Guo, 2013) sehingga suatu merek dapat menggambarkan bahwa produk tersebut diperuntukkan bagi pria atau wanita.

Dari uraian tersebut dapat dilihat betapa strategisnya peran merek bagi sebuah produk, sehingga memberi nama merek pada sebuah produk, membangun dan mengembangkan merek menjadi hal yang sangat penting dan harus di kelola dengan sungguh-sungguh. Bagi perusahaan yang sudah lama memiliki merek maka langkah berikutnya adalah mengembangkan merek tersebut, namun bagi perusahaan atau produk baru yang akan dipasarkan maka menentukan nama merek menjadi sebuah keputusan yang harus diambil dengan pemikiran matang termasuk menentukan sasaran pasar dari produk tersebut.

Pada penelitian ini pertanyaan penelitian yang muncul adalah, bagaimana membangun merek yang baik melalui brand personality dan gender brand personality dikaitkan dengan minat beli. Penelitian ini di fokuskan bagi perusahaan atau produk baru yang belum memiliki merek. Penelitian ini bersifat kualitatif dengan dengan metode pengumpulan data menggunakan metode library research, yaitu dengan menggunakan buku, tulisan ilmiah dan artikel lainnya yang relevan dengan topik yang diteliti sebagai sumber data (Hadi, 1981). Setelah data didapat maka data dianalisis menggunakan metode induktif di sesuaikan dengan topik penelitian ini, yaitu dengan melihat fakta-fakta dan hasil penelitian-penelitian terdahulu kemudian diambil kesimpulan. 


\section{KAJIAN TEORI}

\section{Brand Personality}

Menurut Aaker dalam Lee dan Kang, Brand personality adalah seperangkat karakteristik manusia yang terkait dengan merek, dan Aaker juga mengindentifikasi 5 (lima) dimensi kepribadian merek yaitu : sincerity (ketulusan), excitement (kegembiraan), competence (kompetensi), sophistication (kecanggihan) dan ruggedness (ketangguhan), adapun atribut kelima dimensi brand personality tersebut masingmasing adalah (Lee \& Kang, 2013) :

1. Atribut ketulusan yaitu down to earth, nyata dan jujur

2. Atribut kegembiraan yaitu berani, menarik, imajinatif dan kontemporer.

3. Atribut kompetensi yaitu cerdas, andal, aman dan percaya diri.

4. Atribut kecanggihan yaitu glamor, kelas atas, tampan dan menawan.

5. Atribut ketangguhan yaitu tangguh, di luar ruangan, maskulin dan barat.

Menurut Keller (1993) kepribadian merek itu dapat memenuhi fungsi simbolis atau ekspresi diri bagi konsumen (Wu, Klink, \& Guo, 2013), jadi merek juga dapat menjadi media untuk mengekspresikan diri konsumen.

\section{Gender Brand Personality}

Menurut Grohmann (2009) konsumen juga membutuhkan merek untuk mengekspresikan diri dari berbagai dimensi termasuk maskulinitas dan femininitas, konsumen merasa perlu meningkatkan derajat maskulinitas dan famininitas diri mereka sendiri (Wu et al., 2013). Bahkan Grohmann mengenalkan skala gender brand personality yang terdiri dari skala Masculine Brand Personality (MBP) skala Feminin Brand Personality (FBP) dimana masing-masing skala mewakili sifat-sifat tertentu (Wu et al., 2013), yaitu :

1. MBP mewakili sifat petualang, agresif, berani, dominan dan kokoh

2. FBP mewakili sifat penuh perasaan, rapuh, anggun, sensitif, manis dan lembut

\section{Minat Beli}

Dodds, Monroe dan Grewal (1991) dalam Murwanto dan Indriana (2016) mengatakan minat beli adalah suatu kemungkinan dimana seseorang atau calon konsumen bermaksud untuk membeli suatu produk (Murwanto \& Indriana, 2016). 
Karena berkaitan dengan minat maka pembelian tersebut belum dilaksanakan dan indikator minat beli diidentifikasi sebagai berikut (Naibaho \& Yuliati, 2017) :

1. Minat transaksional yaitu kecenderungan seseorang untuk membeli

2. Minat referensial yaitu kecenderungan seseorang untuk mereferensikan produk kepada orang lain

3. Minat preferensial menggambarkan seseorang yang memiliki preferensi utama pada produk tersebut.

4. Minat eksploratif yaitu minat yang menggambarkan perilaku seseorang yang selalu mencari informasi tentang produk yang diminatinya untuk mendukung sifat-sifat positif dari produk tersebut.

\section{PEMBAHASAN}

Sebuah merek lahir tentunya sudah melalui proses yang panjang, banyak faktor yang dipertimbangkan dalam membuat, memilih dan menetapkan sebuah merek. Daly dan Moloney (2004) mengatakan ada dua aspek yang harus di perhatikan pada pembentukan sebuah merek yaitu (Yoga Santoso \& Rezeky L Toruan, 2018) :

1. Segi tangible aspects meliputi nama, logo, slogan dan kemasan

2. segi intangible aspects meliputi nilai dan citra

Penelitian yang dilakukan oleh Davies, Rojas, Whelan, Mete dan Loo menunjukkan bahwa kepribadian merek tidak dilandasi oleh kepribadian manusia tetapi didasarkan pada persepsi manusia, mereka mengatakan bahwa kepribadian merek dibentuk melalui pensinyalan dimana perusahaan membentuk dan menentukan merek dan memberikan sinyal melalui merek tersebut kepada calon konsumen (Davies, RojasMéndez, Whelan, Mete, \& Loo, 2018). Calon konsumen mempersepsikan sendiri kepribadian dari sebuah merek yang mereka ketahui, kemudian disesuaikan dengan kepribadian masing-masing. Dimensi kepribadian manusia dan sifat atau atribut yang digunakan untuk mengukurnya menurut (McCrae dan John, 1992) adalah (Davies et al., 2018) adalah :

- Extraversion (aktif, tegas, energik, antusias, keluar dan banyak bicara);

- Agreeableness (apresiatif, pemaaf, dermawan, baik hati, simpatik dan saling percaya); 
- Conscientiousness (efisien, terorganisir, perencanaan, dapat diandalkan, bertanggung jawab dan teliti);

- Neuroticism (cemas, mengasihani diri sendiri, tegang, sensitif, tidak stabil dan mengkhawatirkan); dan

- Openness (artistik, penasaran, imajinatif, wawasan, orisinal dan kepentingan luas).

Persepsi calon konsumen terhadap brand personality sebuah merek dapat terlihat apabila merek tersebut diperkenalkan dan dipublikasikan melalui media massa dimana tidak ada komunikasi langsung antara produsen/pemilik merek dengan calon konsumen. Menurut Morissan (2016) orang atau calon konsumen cenderung akan melakukan seleksi terhadap informasi yang dilihat atau di dengar melalui media massa, yang akan membantu calon konsumen memilih, mengingat dan menginterpretasikan informasi yang diterimanya. Proses selektif tersebut terdiri dari (Morissan, 2016) :

1. Penerimaan informasi selektif, merupakan proses dimana orang hanya akan menerima informasi yang sesuai dengan sikap atau kepercayaan yang telah dimiliki sebelumnya.

2. Ingatan selektif, mengasumsikan bahwa orang tidak akan mudah lupa atau sangat mengingat terhadap pesan-pesan yang sesuai dengan sikap atau kepercayaan yang sudah dimiliki sebelumnya.

3. Persepsi selektif, dimana orang akan memberikan interpreatsinya terhadap setiap pesan yang diterimanya sesuai dengan sikap dan kepercayaan yang sudah dimiliki sebelumnya.

Proses selektif tersebut memperlihatkan bahwa jika sebuah merek diperkenalkan melalui media massa maka persepsi calon konsumen akan sangat penting, sehingga membentuk brand personality yang sesuai dengan target pasar menjadi sangat strategis dalam memunculkan minat beli pada calon konsumen.

Membangun merek agar memiliki persepsi yang baik dan bernilai tinggi tidaklah mudah, membutuhkan waktu yang panjang dan biaya yang besar serta konsistensi perusahaan. Beberapa merek terkenal bahkan beberapa kali mengganti merek dengan berbagai alasan, yang tujuannya adalah mempertahankan atau meningkatkan nilai merek dan pada akhirnya konsumen tetap membeli produk mereka bahkan dapat menarik konsumen potensial. Sebagai contoh adalah merek National asal jepang untuk kategori produk alat elektronik rumah tangga yang berganti nama menjadi Panasonic, menurut 
Rinaldi Sjarif, Direktur PT National Panasonic Gobel (2004) alasan penggantian merek tersebut didasarkan pada kata National yang dipersepsikan oleh konsumen di luar Jepang khusus untuk pengguna lokal di Jepang sehingga dengan mengganti menjadi Panasonic akan dapat fokus dalam hal merek, kategori produk, saluran distribusi dan servis (Murwanto \& Indriana, 2016). Sebelum berganti menjadi Panasonic, pihak manajemen National menyandingkan nama merek National/Panasonic agar konsumen memahami bahwa kedua merek tersebut berada dalam satu manajemen dan kategori produk yang sama, butuh waktu 6 (enam) tahun untuk melakukan sosialisasi merek National/Panasonic sebelum benar-benar berganti menjadi Panasonic dan merek National dihapus (Murwanto \& Indriana, 2016)

Produk pioneer (pelopor) biasanya membutuhkan waktu lebih lama dalam membangun awareness dibandingkan produk pengikut. Beberapa produk pelopor di Indonesia yang masih mendominasi pasar misalnya Aqua (air mineral dalam kemasan), Sanyo (pompa air), Teh Botol Sosro (teh botol), Baygon (pembasmi nyamuk), Honda (sepeda motor), Coke (minuman cola), Gillete (pisau cukur) dan Sony (produk elektronik) sedangkan ada juga beberapa produk pelopor yang gagal jadi pemimpin pasar misalnya Odol (pasta gigi) sekarang dikuasai Pepsodent, Wordstar (program pengolah kata) sekarang dikuasai MS Word, Supermi (mi instan) dikuasai Indomie dan Atari (Video game) dikuasai oleh Sony Play Station (Tjiptono, 2011). Bagi produk pengikut atau imitator walaupun harus siap bersaing secara ketat dengan produk pelopor tetap masih punya peluang berkembang dan bahkan bisa menguasai pasar.

Setiap dimensi brand personality juga perlu dipahami dalam rangka membangun merek, adapun dimensi tersebut adalah sincerity (ketulusan), excitement (kegembiraan), competence (kompetensi), sophistication (kecanggihan) dan ruggedness (ketangguhan) (Lee \& Kang, 2013).

1. Dimensi sincerity (ketulusan), dimana atributnya adalah down to earth, nyata dan jujur yang apabila diidentikkan dengan sifat manusia akan mencerminkan sifat-sifat yang sederhana seperti ceria dan berjiwa muda

2. Dimensi excitement (kegembiraan) dengan atribut berani, menarik, imajinatif dan kontemporer menggambarkan karakter seseorang yang dinamis yang berani melakukan perbedaan dan inovasi serta selalu . 
3. Dimensi competence (kompetensi) dengan atribut cerdas, andal, aman dan percaya diri dapat menggambarkan pribadi seseorang yang dapat diandalkan dan diakui kemampuannya serta percaya diri.

4. Dimensi sophistication (kecanggihan) yaitu glamor, kelas atas, tampan dan menawan dapat menggambarkan pribadi yang mempesona, menarik, terbaru.

5. Dimensi ruggedness (ketangguhan) dimana atributnya adalah tangguh, di luar ruangan, maskulin dan barat sering melekat sebagai pribadi yang gagah dan tangguh, senang bertualang, tidak mudah menyerah

Apabila seorang pengguna smartphone selalu menggunakan merek terbaru, maka smartphone tersebut memiliki kepribadian merek dengan memenuhi dimensi sophistication. Bagi pengguna, smartphone tersebut dapat membantu mengekspresikan bahwa dirinya adalah orang yang glamor dan selalu update terhadap perkembangan teknologi.

Setiap merek pada dasarnya memiliki kepribadian, dalam hal gender brand personality sebuah merek dapat dipersepsikan berbeda antara produsen dengan konsumen. Seperti misalnya merek minuman Coca Cola, pada tahun 1982 meluncurkan produk dengan nama diet coke. Dalam perjalanan merek tersebut, ternyata kaum pria tidak terlalu berminat, karena walaupun kaum pria sadar kalori, tetapi mereka berasumsi bahwa produk dengan kata-kata diet lebih ditujukan kepada kaum wanita, sehingga pada tahun 2006 Coca Cola meluncurkan produk sejenis dengan nama coke zero (Wu et al., 2013). Dari hal tersebut terlihat ada perbedaan persepsi antara Coca Cola dengan konsumennya terutama kaum pria, sehingga dapat disimpulkan bahwa kesalahan dalam penargetan gender sebuah merek dapat mengakibatkan berkurangnya minat beli.

Gender brand personality dapat dilihat dari susunan huruf dan pengucapan, misalnya penelitian yang dilakukan oleh Crystal (1995), nama dengan vokal depan huruf "i” lebih banyak digunakan untuk nama wanita (misalkan Tina, Linda) dibandingkan nama pria, sedangkan menurut Klink (2000) pada penelitian merek fiktif shampo "Tidip" yang berisi vokal depan huruf "i" dianggap lebih feminin dibandingkan dengan "Todip", Klink juga mengatakan nama merek dengan vokal depan huruf "i” dan "e" dapat menggambarkan produk yang lebih kecil, lebih terang, lebih ringan, lebih tipis, lebih lembut, lebih cepat, lebih dingin, lebih pahit, lebih ramah, lebih cantik dan 
lebih feminin (Wu et al., 2013), sehingga nama yang mirip tetapi dengan perbedaan vokal depan " $\mathrm{i}$ " dan "o" dapat membedakan gender brand personality dalam menentukan target konsumen berdasarkan gender.

\section{Merek yang efektif}

Nama merek pada umumnya adalah elemen inti dari sebuah merek, tetapi elemen visual juga berperan penting dalam membentuk brand awareness, logo dan simbol dapat membantu konsumen untuk membangun persepsi terhadap sebuah merek atau perusahaan sehingga apabila merek dibuat dengan unsur visual yang tepat maka akan mudah dikenali oleh konsumen (Yoga Santoso \& Rezeky L Toruan, 2018).

Dalam membuat merek hendaknya juga memasukkan unsur warna sebagai pembentuk identitas merek yang utama selain tulisan karena salah satu cara untuk membentuk identitas merek yang efektif adalah dengan memanfaatkan unsur visual yang merangsang penglihatan, dimana unsur visual yang dominan adalah warna (Swasty \& Utama, 2017). Ada anggapan dalam benak konsumen, warna tertentu dapat mencerminkan gender atau jenis kelamin tertentu, dapat juga mencerminkan kepribadian tertentu. Dalam memilih dan menentukan merek, sangat penting mempertimbangkan warna dari simbol yang digunakan, karena hal ini dapat membantu produk atau merek untuk memasuki target konsumen yang diinginkan.

Penelitian yang dilakukan oleh Naibaho dan Yuliati terhadap produk Body Mist The Body Shop, ditemukan bahwa brand personality secara keseluruhan berpengaruh positif terhadap minat beli, sedangkan secara parsial elemen brand personality yang pengaruhnya paling signifikan terhadap minat beli adalah elemen ruggedness (ketangguhan) dan competence (kompetensi) (Naibaho \& Yuliati, 2017). Walaupun kategori produknya terbatas pada produk perawatan tubuh, tetapi dari penelitian tersebut terlihat bahwa brand personality dengan berbagai dimensinya memang dapat memunculkan minat beli.

\section{KESIMPULAN}

Tidak dapat dipungkiri bahwa merek menjadi faktor yang sangat strategis bagi pemasar, maupun pemilik produk, bagi produk pelopor perlu merintis dengan susah payah agar dapat diterima oleh konsumen. Sebagai contoh merek Aqua sebagai pelopor produk minuman air mineral dalam kemasan, melalui reputasi yang baik maka nama 
merek Aqua sampai pada tahap disamakan dengan nama produk dan memiliki nilai merek yang sangat tinggi.

Dari pembahasan di atas, dapat disimpulkan bahwa merek adalah hal yang harus dimiliki dan melekat pada produk apabila menginginkan produk dapat diterima oleh konsumen. Dalam membuat merek, sebuah merek harus memiliki aspek tangible dan intangible. Aspek tangible yang terdiri dari nama, logo, slogan dan kemasan, hal ini berkaitan dengan persepsi yang ingin dibangun dari merek tersebut. Secara visual, logo dibuat dengan baik termasuk pemberian warna agar mudah diingat, mudah merepresentasikan sebuah produk dalam hal manfaat dan kegunaan serta mencerminkan kualitas produk. Aspek intangible yang terdiri dari nilai dan citra merek akan didapat dari reputasi merek tersebut.

Dalam membuat, menetapkan dan membangun merek, hendaknya diperhatikan dengan seksama brand personality seperti apa yang akan dimiliki oleh merek tersebut, jika sudah diketahui target pasar yang akan dimasuki akan lebih mudah membentuk brand personality pada merek tersebut. Jika target pasar produk tersebut adalah orangorang yang bersifat sederhana dan ceria maka brand personality difokuskan kepada dimensi sincerity (ketulusan), jika target pasarnya adalah orang-orang yang berkepribadian dinamis fokus pada dimensi excitement (kegembiraan), jika ingin target pasarnya orang-orang yang percaya diri maka fokus pada dimensi competence (kompetensi), jika target pasarnya orang-orang yang senang glamor dan tampil mempesona dapat fokus pada dimensi sophistication (kecanggihan) dan jika ingin target pasar orang-orang yang senang bertualang, berpenampilan gagah maka fokus pada dimensi ruggedness (ketangguhan). Alternatif lain adalah gabungan dari beberapa dimensi brand personality yang ada.

Jika gender termasuk faktor yang dipertimbangkan dalam memilih target pasar maka nama merek harus disesuaikan, terutama pada tulisan dan pengucapan merek serta warna yang sesuai pada tampilan logonya.

Pada penelitian ini hanya terbatas pada brand personality dan gender brand personality produk baru dikaitkan dengan minat beli konsumen, setelah merek tersebut dapat diterima oleh konsumen dengan melakukan pembelian maka selanjutnya harus membangun dan menjaga reputasi merek tersebut menjadi semakin baik sehingga dapat menaikkan nilai merek dan citra merek. Sehubungan dengan hal tersebut penulis 
menyarankan penelitian selanjutnya adalah brand personality dan gender brand personality dikaitkan dengan nilai merek dan citra merek, selain itu perlu diteliti juga brand personality dan gender brand personality untuk rebranding.

\section{DAFTAR PUSTAKA}

Davies, G., Rojas-Méndez, J. I., Whelan, S., Mete, M., \& Loo, T. (2018). Brand personality: theory and dimensionality. Journal of Product and Brand Management, 27(2), 115-127. https://doi.org/10.1108/JPBM-06-2017-1499

Hadi, S. (1981). Metodologi Research : Untuk Penulisan Paper, Skripsi, Thesis dan Desertasi (XI). Yogyakarta: Yayasan Penerbitan Fakultas Psikologi UGM Yogyakarta.

Lee, H. J., \& Kang, M. S. (2013). THE EFFECT OF BRAND PERSONALITY ON BRAND RELATIONSHIP, ATTITUDE AND PURCHASE INTENTION WITH A FOCUS ON BRAND COMMUNITY. In Academy of Marketing Studies Journal (Vol. 17).

Merek Termahal di Indonesia 2018. (n.d.). Retrieved from https://industri.kontan.co.id/news/inilah-10-merek-paling-bernilai-versibrandz\%0A

Morissan, M. A. (2016). Psikologi Komunikasi (3rd ed.; R. Sikumbang, Ed.). Ghalia Indonesia.

Murwanto, H., \& Indriana, D. (2016). Brand Replacement : Factors Affecting Customers' Purchase Intention. Proceedings Of The 1st International Conference On Bussiness, Economics, Socio-Culture And Tourism, 225-246. Retrieved from https://sites.google.com/a/usm.ac.id/ic-best/proceedings

Naibaho, A., \& Yuliati, A. L. (2017). PENGARUH BRAND PERSONALITY TERHADAP MINAT BELI PRODUK BODY MIST (Studi pada The Body Shop di Trans Studio Mall Bandung). Jurnal Computech \& Bisnis, 11(1), 25-38.

Rahab. (2009). PENERAPAN MANAJEMEN MEREK PADA USAHA KECIL DAN MENENGAH (UKM). Jurnal Bisnis Dan Ekonomi, 16(1), 18-25.

Rizan, M., Handayani, K. L., \& Kresnamurti, A. (2015). PENGARUH CITRA MEREK DAN KUALITAS PRODUK TERHADAP KEPUTUSAN PEMBELIAN (STUDI BANDING KONSUMEN INDOMIE DAN MIE SEDAAP). In Jurnal Riset Manajemen Sains Indonesia (JRMSI)| (Vol. 6).

Swasty, W., \& Utama, J. (2017). Warna sebagai Identitas Merek pada Website. ANDHARUPA: Jurnal Desain Komunikasi Visual \& Multimedia, 3(01), 1-16. https://doi.org/10.33633/andharupa.v3i01.1294 
Tjiptono, F. (2011). Manajemen dan Strategi Merek. Andi Offset.

Undang-Undang Republik Indonesia Nomor 15 Tahun 2001 Tentang Merek. , (2001).

Wu, L., Klink, R., \& Guo, J. (2013). Creating gender brand personality with brand names: The effects of phonetic symbolism. Journal of Marketing Theory and Practice, 21(3), 319-329. https://doi.org/10.2753/MTP1069-6679210306

Yoga Santoso, P., \& Rezeky L Toruan, R. M. (2018). STRATEGI MARKETING PUBLIC RELATIONS DALAM REBRANDING HSBC INDONESIA UNTUK MEMBENTUK BRAND AWARENESS. Jurnal Pustaka Komunikasi, 1(1), 1-14. https://doi.org/https://doi.org/10.32509/pustakom.v1i1.512 